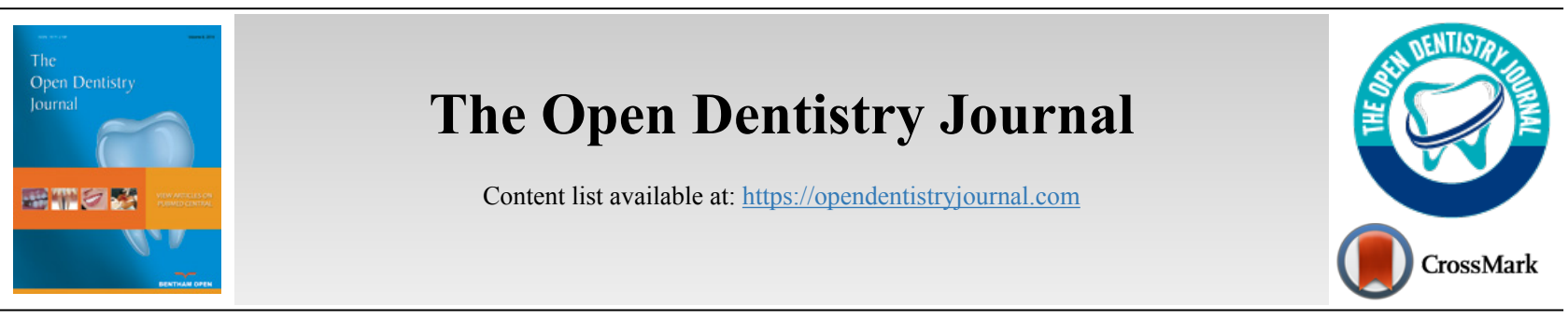

RESEARCH ARTICLE

\title{
Sensitivity and Specificity of Mandibular Third Molar Calcification at Chronological Age and Hand Wrist Maturation Stage to Discriminate Between Female and Male at Pubertal Growth Period
}

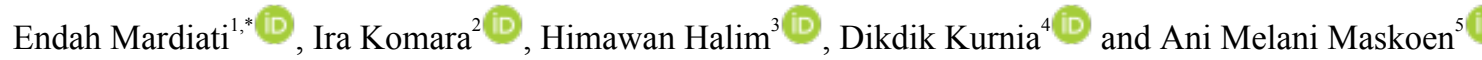 \\ 'Department of Orthodontics, Faculty of Dentistry, Universitas Padjadjaran-Bandung, Bandung, Indonesia \\ ${ }^{2}$ Department of Periodontics, Faculty of Dentistry, Universitas Padjadjaran-Bandung, Bandung, Indonesia \\ ${ }^{3}$ Department of Orthodontics, Faculty of Dentistry, Trisakti University, Jakarta, Indonesia \\ ${ }^{4}$ Department of Chemistry, Faculty of Mathematics and Natural Science, Universitas Padjadjaran-Bandung, Bandung, Indonesia \\ ${ }^{5}$ Department of Oral Biology, Faculty of Dentistry, Universitas Padjadjaran-Bandung, Bandung, Indonesia
}

\section{Abstract:}

Background:

The mandibular third molar is the last tooth that is not completely developed by the time pubertal growth has been finished. Maturation of the mandibular third molar is one of the physiological maturation indicators that can be used to determine the stage of pubertal growth.

\section{Objective:}

The aim of the study was to determine the sensitivity and specificity of mandibular third molar calcification at chronological age and hand wrist maturation stage to discriminate between female and male at pubertal growth period.

Methods:

It is a retrospective study with a cross-sectional approach using panoramic and hand-wrist digital radiographs of 279 females and 144 males, age 8-17 years, with a total of 423 panoramic radiographs and 423 hand-wrist radiographs. Statistical analysis was performed using Excel Mega Stat. ANOVA to analyze the differences between mandibular third molar calcification at chronological age and hand-wrist maturation stage, and t-test was used to analyze the differences between females and males. Spearman rank correlation was used for the analysis of the correlation between mandibular third molar calcification with chronological age and hand-wrist maturation stage; sensitivity and specificity were used to discriminate the pubertal growth period between mandibular third molar calcification and hand-wrist maturation stage.

Results:

There were significant differences found in mandibular third molar crown maturation stage B and C, but no significant difference was observed between mandibular third molar stage A, D, E, F, G and H, between females and males. The highest percentage of mandibular third molar crown formation in females was observed at stage D (6.68\%) at MP3u, and in males, it was observed at stage D (8.83\%) at SMI-4. The highest percentage of root formation in females was stage E $(8.24 \%)$ at the SMI-10 stage, and males stage F $(4.86 \%)$ at MP3u. The correlation was observed between mandibular third molar calcification with hand-wrist, females 0.22 and males 0.43 , and chronological age 0.60 for females and 0.69 for males. The highest sensitivity of mandibular third molar calcification of $97.0 \%$ was observed in female at SMI- 4 of hand-wrist maturation with specificity of $100 \%$, while in male, a sensitivity of $94.5 \%$ was observed at SMI-2 stage with a specificity of $99.99 \%$.

\section{Conclusion:}

There were significant differences found in mandibular third molar calcification between females and males except for stage B and stage C; weak correlation was observed between mandibular third molar calcification and hand-wrist, and moderate correlation was observed with chronological age. The sensitivity and specificity in females and males indicate that mandibular third molar calcification is only useful for diagnosing the prepubertal growth phase.

Keywords: Mandibular third molar, Hand-wrist, Chronological age, Pubertal growth, Molar, Crown, Spearman. 


\section{INTRODUCTION}

The development of tooth calcification is one of the physiological maturation indicators that can be used to predict pubertal growth. The development of mandibular third molar based on chronological age varies greatly from the initial formation until the completion and can be used to estimate chronological age at pubertal growth period [1 - 3]. In the Orthodontic treatment, the evaluation of mandibular third molar development is important to estimate whether it needs to be extracted or not because mandibular third molar eruption can disrupt the stability of the orthodontic treatment results $[4$, 5]. The development of mandibular third molar as other teeth can be observed using a panoramic radiograph which is routinely used for assessing dental maturation in orthodontic treatment. The study by Thorson et al. shows that mandibular third molar is accurate and precise as an indicator of chronological age [6]. The development of the mandibular third molar is under strong genetic control and has less environmental influence compared to other physiological maturation [7].

The most common method for assessing the dental calcification stage is Demirjian and Goldstein method which consists of 8 stages A to H. Stages A to D represent the crown formation starting from the appearance of the cusp until the completion of the crown, and stage $\mathrm{E}$ to stage $\mathrm{H}$ represent root formations from radicular bifurcation to apical closing. The stages of tooth development proposed by the Demirjian and Goldstein method were based on the ratio of the crown and root formation and not on the changes of linear measurements.

Previous studies have found that the mineralization of the mandibular third molar is a population-specific process and varies according to chronological age in different ethnic groups. Therefore, estimation of tooth development should ideally be carried out in the same population [8 - 12]. Many studies conducted in different countries have analyzed the levels of mandibular third molar calcification based on chronological age and hand-wrist maturation stage at the pubertal growth period [13 - 17]. Considering that the level of mandibular third molar calcification is influenced by many factors, it is possible that Indonesian subjects have different maturation stages compared to other populations. The purpose of the study was to determine the sensitivity and specificity of mandibular third molar calcification at chronological age and hand wrist maturation stage to discriminate between females and males at pubertal growth period.

\section{MATERIALS AND METHODS}

This was a retrospective study with a cross-sectional approach. The subjects consisted of 279 females and 144 males, ages 8 to 17 years, with each subject providing good quality digital panoramic and hand-wrist radiographs, making a total of 423 panoramic and 423 hand-wrist radiographs. All participants were orthodontic patients in Orthodontic Clinic, Faculty of Dentistry, University of Padjadjaran. Inclusion cri-

\footnotetext{
* Address correspondence to this author at the Department of Orthodontics, Faculty of Dentistry, Universitas Padjadjaran, Jl. Raya Bandung-Sumedang km.21, Bandung, Indonesia; Tel: +62 812-2359-797;

E-mail: endah_mardiati@yahoo.com
}

teria involved Indonesian, healthy patients, free from systemic or serious illness, who never had previous orthodontic treatment, or trauma on the face, hand and wrist, and those not missing mandibular third molar on both sides of the lower jaw. Hand-wrist maturation was analyzed by the Fishman method [18], and mandibular third molar calcification was done according to modification of Demirjian and Goldstein method on panoramic radiographs [8].

\subsection{Statistical Analysis}

ANOVA was used to analyze the differences between mandibular third molar calcification in chronological age and hand-wrist maturation stage, and post hoc using t-test was used to analyze the differences between females and males. Spearman rank correlation was used to analyze the correlation between mandibular third molar calcification with chronological age and hand-wrist maturation stage at pubertal period $(\mathrm{P}<0.05)$. Sensitivity and specificity tests were carried out using screening test Thornier-Remain $2 \times 2$. Statistical analysis was performed using Excel Mega Stat. Gaussian distribution was as follows: male $\mathrm{P}=0.1231$ and female $\mathrm{P}=$ 0.0956 . The reliability test was conducted by taking 10 random panoramic and hand-wrist radiographs of female and male participants. Repeated measurements were done 3 times by three researchers, with 2-week intervals. Cohen's Kappa interrater coefficient showed no significant difference in mandibular third molar calcification ( 0.852 in females and 0.873 in males) and hand-wrist maturation (females 0.910 and 0.879 in males).

Hand-wrist maturation stage of Fishman method consists of 11 stages, which can be divided into three stages of maturation: pre-pubertal growth (SM-1 to SMI-4), pubertal growth (SMI-5 to SMI-7) and post-pubertal growth (SMI-8 to SMI-11).

\section{RESULTS}

The distribution of subjects according to gender and chronological age is shown in Table 1. Mandibular third molar calcification stage of females and males in chronological age is shown in Table 2. The highest mandibular third molar calcification was achieved by 81 female subjects (29\%) at 12.65 years while in male 40 subjects $(27.77 \%)$ at 12.70 years; thus no significant difference was observed between females and males $(P>0.05)$. Calcification mandibular third molar stage $\mathrm{H}$ only occurred in 2 male subjects $(1.39 \%)$ at 17.00 years old. Mandibular third molar calcifications stage B and C differed significantly between females and males $(P<0.05)$, while mandibular third molar calcification stage A to $\mathrm{G}$ did not differ significantly between male and female subjects $(P>0.05)$ (Table 2). The distribution of mandibular third molar crown calcification stage A, B, C and D in females was at $10.9-12.65$ years and males at 10.0-12.70 years. Root formation of mandibular third molar stage E, E, G, in females was at 14.5-15.57 years, and in males, the stage E, F, G was at 12.70-17.00 years. This indicates that root formation was not finished at pubertal growth, and only two male subjects reached stage $\mathrm{H}$ (Table 2). 
Table 1. Distribution of female and male subjects according to gender and chronological age (years).

\begin{tabular}{|c|c|c|c|c|c|c|c|c|c|c|c|}
\hline Age (Year) & 8 & 9 & 10 & 11 & 12 & 13 & 14 & 15 & 16 & 17 & Total \\
\hline Male & - & 19 & 21 & 15 & 15 & 26 & 18 & 11 & 13 & 6 & 144 \\
\hline Female & 5 & 32 & 28 & 46 & 33 & 43 & 32 & 22 & 25 & 13 & 279 \\
\hline
\end{tabular}

Table 2. The differences of mandibular M3 calcification stage between females and males in chronological age (years).

\begin{tabular}{|c|c|c|c|c|c|c|c|c|}
\hline \multirow{2}{*}{ Stage } & \multicolumn{3}{|c|}{ Females } & \multicolumn{3}{c|}{ Males } & \multicolumn{2}{c|}{$\begin{array}{c}\text { Comperativ } \\
\text { Females vs Males }\end{array}$} \\
\cline { 2 - 9 } & $\mathbf{n}$ & Average & std & $\mathbf{n}$ & Average & std & t -test & $\boldsymbol{p}$-value \\
\hline 0 & 37 & 11.59 & 2.68 & 18 & 11.00 & 2.3 & 4.26 & $0.00^{*}$ \\
\hline A & 23 & 10.09 & 1.62 & 10 & 10.00 & 0.82 & 0.7 & 0.2433 \\
\hline B & 32 & 10.28 & 1.35 & 14 & 10.07 & 1.14 & 2.46 & $0.009^{*}$ \\
\hline C & 35 & 11.34 & 1.21 & 27 & 11.74 & 1.75 & -5.66 & $0.000^{*}$ \\
\hline D & 81 & 12.65 & 1.64 & 40 & 12.70 & 1.38 & -1.2 & 0.1155 \\
\hline E & 40 & 14.5 & 1.24 & 18 & 14.42 & 1.69 & 0.98 & 0.1661 \\
\hline F & 21 & 15.57 & 1.03 & 13 & 15.54 & 1.27 & 0.32 & 0.3740 \\
\hline G & 7 & 15.57 & 2.64 & 2 & 17.00 & 1.41 & -0.71 & 0.2495 \\
\hline H & - & - & - & 2 & 17.00 & 0 & - & - \\
\hline *Significant & - & - & - & - & - & - & - & - \\
\hline
\end{tabular}

The stage of mandibular third molar calcification at handwrist maturation stage is shown in Tables 3 and $\mathbf{4}$. The highest calcification of crown formation was at stage D at MP3u $(6.68 \%)$ for females and males at SMI-4 (Sesamoid/S), 8.33\%. The highest root formation of mandibular third molar calcification for female stage E was $8.24 \%$ at SMI-10 (MP3u), while in males, it was at stage F $(4.86 \%)$ at SMI-10 (MP3u) The last stage for females at stage G was $2.15 \%$ at SMI-11(Ru) and males $0,16 \%$; only male samples $(1.39 \%)$ had reached stage $\mathrm{H}$ on SMI-11 (Ru) (Table 4). The mandibular third molar calcification in female subjects was at SMI-4 (S stage) of handwrist maturation with $97.0 \%$ sensitivity and $100 \%$ specificity; in males, sensitivity of $94.5 \%$ and specificity of $99.99 \%$ were observed at SMI-2 (stage MP3). SMI-4 (stage S) and SMI-2 (stage MP3) were prepubertal growth stages of hand-wrist maturation. This result indicates that the ability of mandibular third molar calcification for identifying pubertal growth at the hand-wrist maturation stage was only for prepubertal growth stage (Table 5). The correlation between mandibular third molar and hand-wrist maturation stage was estimated at 0.43 in males and 0.22 in females, which was found to be lower than the correlation observed between mandibular third molar calcification and chronological age, with females showing 0.60 and males $0.69(\mathrm{P}<0.0001)$ (Table 6).

\section{DISCUSSION}

In the field of orthodontic treatment, the determination of diagnosis, treatment plan, and appropriate time of orthodontic treatment in patients during pubertal growth is more accurate than chronological age using physiological maturation indicators. There are various physiological maturation indicators to assess pubertal growth status, such as height, weight, secondary sexual maturation, dental and skeletal maturation [19]. Dental maturation can be assessed from either the phase of tooth eruption or the stage of tooth calcification. Tooth eruption is influenced by local or systemic conditions but not tooth calcification, therefore tooth calcification is more reliable for the determination of pubertal growth stage $[8,20$, 21]. Demirjian and Goldstein proposed a method for estimation of dental maturity on panoramic radiograph for the seven left permanent mandibular teeth at eight calcification stages. Stages A, B, C, D were for crown formation and stages E, F, G, H were for root formation (Fig. 1) [8]. The use of mandibular third molar calcification has an advantage because mandibular third molar calcifications still continue even though pubertal growth has been completed; therefore, it can be used to determine the stage of pubertal growth [8, 9, 21, 22].

Tabel 3. The highest percentage of crown formation of mandibular M3 calcification on hand-wrist maturation stage in females and males.

\begin{tabular}{|c|c|c|c|}
\hline- & Stage Hand-Wrist & M3 Calcification Stage & Percentage \\
\hline Male & SMI-4 (S) & D & 8.33 \\
\hline Females & SMI-10 (MP3u) & D & 6.68 \\
\hline
\end{tabular}

Tabel 4. The highest percentage of root formation of mandibular M3 calcification on hand-wrist maturation stage in females and males.

\begin{tabular}{|c|c|c|c|}
\hline- & \multicolumn{2}{|c|}{ Females } & - \\
\hline- & Stage Hand-Wrist & M3 Calcification Stage & Percentage \\
\hline Males & SMI-10 (MP3u) & F & 4.86 \\
\hline Females & SMI-10 (MP3u) & E & 8.24 \\
\hline
\end{tabular}

Tabel 5. Percentage of sensitivity and specificity of mandibular M3 calcification stage and hand-wrist maturation stage in female and male subjects.

\begin{tabular}{|c|c|c|c|c|c|c|}
\hline- & \multicolumn{3}{|c|}{ Females } & \multicolumn{3}{c|}{ Males } \\
\cline { 2 - 7 } & $\begin{array}{c}\text { Stage } \\
\text { Hand-Wrist }\end{array}$ & Sensitivity & Specificity & $\begin{array}{c}\text { Stage } \\
\text { Hand-Wrist }\end{array}$ & Sensitivity & Specificity \\
\hline Highest & SMI-4 (S) & 97.0 & 100.00 & $\begin{array}{c}\text { SMI-2 } \\
(\mathrm{MP} 3)\end{array}$ & 94.5 & 100.00 \\
\hline Lowest & $\begin{array}{c}\text { SMI-11 } \\
(\mathrm{Ru})\end{array}$ & 2.0 & 100.00 & $\begin{array}{c}\text { SMI-11 } \\
(\mathrm{Ru})\end{array}$ & 7.6 & 100.00 \\
\hline
\end{tabular}

Tabel 6. Correlation of mandibular M3 with hand-wrist and chronological age of females and males.

\begin{tabular}{|c|c|c|c|c|c|c|}
\hline \multirow{2}{*}{ Stages } & \multicolumn{3}{|c|}{ Females } & \multicolumn{3}{c|}{ Male } \\
\cline { 2 - 7 } & $r$ & $t$ & $p$-value & $r$ & $t$ & $p$-value \\
\hline M3 and hand-wrist & 0.22 & 3.71 & $.00013 *$ & 0.43 & 5.61 & $.0001 *$ \\
\hline M3 and chronological age & 0.60 & 12.55 & $.0001 *$ & 0.69 & 11.22 & $.0001 *$ \\
\hline *Significant & - & - & - & - & - & - \\
\hline
\end{tabular}




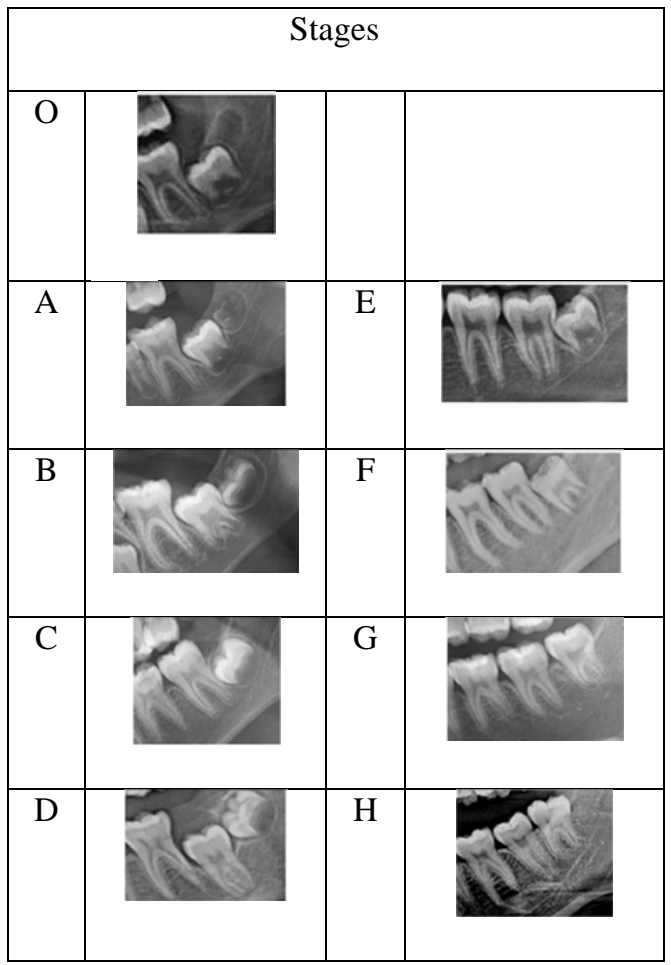

Fig. (1). Stages of mandibular third molar calcification. Stage O shows that calcification of mandibular third molar has not started, while stage A-D represent the crown formation, and stage $\mathrm{E}$ to $\mathrm{H}$ represent the root formation [8].

Width of epiphysis equal to diaphysis:

SMI-1 (PP3 stage ): epiphysis equal to diaphysis at proximal of the third finger

SMI-2 (MP3 stage): epiphysis equal to diaphysis at the middle phalanx of the third finger

SMI-3 (MP5 stage): epiphysis equal to diaphysis at the middle phalanx of the fifth finger

SMI-4 (S stage): the appearance of the adductor sesamoid of the thumb

Capping of epiphysis to diaphysis:

SMI-5 (DP3cap): capping of epiphysis to diaphysis distal phalanx of the third finger

SMI-6 (MP3cap): capping of epiphysis to diaphysis middle phalanx of the third finger

SMI-7 (MP5cap): capping of epiphysis to diaphysis middle phalanx of the fifth finger

Union of epiphysis and diaphysis:

SMI-8 (DP3u): union of epiphysis and diaphysis distal phalanx of the third finger

SMI-9 (PP3u): union of epiphysis and diaphysis proximal phalanx of the third finger

SMI-10 (MP3u): union of epiphysis and diaphysis middle phalanx of the third finger

SMI-11 $(\mathrm{Ru})$ : union of epiphysis and diaphysis of radius

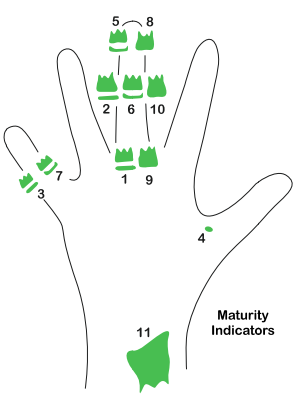

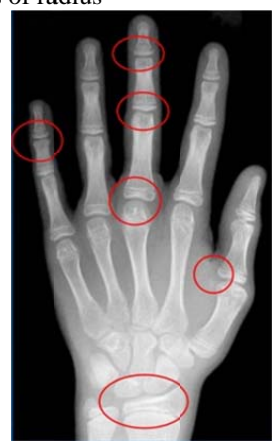

B

Fig. (2). A. Eleven SMIs by Fishman method; B. The location where maturation is determined [18]. 
The evaluation of dental maturation using mandibular third molar on panoramic radiograph would be an adjunctive tool for pubertal growth assessment in combination with hand-wrist maturation stage, but it should be taken into consideration because there are many variations in conjunction with chronological age and hand-wrist maturation [9, 23, 24]. In this study, we used the modification of Demirjian and Goldstein system to assess left mandibular third molar maturation, know its correlation with chronological age and hand-wrist maturation stage, and to test the sensitivity and specificity with respect to hand-wrist maturation $[11,17]$. In Thai subjects, it has been shown that males tend to be more advanced as compared to females in relation to skeletal maturity stages [24], while in Spanish, mandibular third molar crown formation is complete at the age of 14 years and the root formation finishes at an average age of 18.5 years [12]. In a study by Kullman et al., the crown formation of mandibular third molar was completed at 13.5 years and root formation began at about 15.1 years completed at an average age of 19.3 years [25]. In the Australian subject, crown completion of mandibular third molar at stage $\mathrm{A}$ to $\mathrm{D}$ was found at $14.77 \mathrm{y} \pm 1.68$ years and root formation without closure of the apex (stage G) was observed at a mean age of $19.00 \pm 1.48$ years [23]. In our study, as shown in Table 2, female crown formation of mandibular third molar was observed at 10.09 years which finished at 12.65 years, and root formation of mandibular third molar was observed to start at 14,5 years and stage $G$ at 15.57 years, while for male, the crown formation started at 10.00 years and finished at 12.70 years, and root formation started at 14,42 years and reached stage $G$ at 17 years. Only 2 subjects were at stage $\mathrm{H}$ at 17 years. With respect to the hand-wrist maturation, the highest percentage of mandibular third molar stage $\mathrm{E}$ in female subjects was $8.24 \%$ at MP $3 \mathrm{u}$, while for males, stage D was $8.33 \%$ at $\mathrm{S}$ stage (Table 3 ). This difference can be attributed to different race, ethnicity, sample size and research methods [19].

Many studies have reported the sensitivity and specificity of mandibular third molar maturation as a physiological maturation index. The sensitivity and specificity of mandibular third molar maturation in this study were evaluated in the context of the association between mandibular third molar calcification stage and hand-wrist maturation divided into three categories: pre-pubertal (SMI-1 to SMI- 4)PP3-S), pubertal (SMI=5 to SMI-7), and post-pubertal periods (SMI-8 to SMI-11). The results show that the higher sensitivity in female subjects was $97.0 \%$ with specificity $100 \%$ at SMI-4 of handwrist maturation, while in males, sensitivity was $94.5 \%$ and specificity $99.99 \%$ at SMI-2; both females and males were at the prepubertal stage. The lowest sensitivity of females was at $2 \%$ and males at $7.6 \%$; this indicates that at the end of pubertal growth, the stage of mandibular third molar calcification cannot be used as an indicator of pubertal growth maturation because mandibular third molar calcification was not yet finished in both females and males. This result was in concordance with a previous research indicating dental calcification as only useful for diagnosing the pre-pubertal growth phase [26, 27].

Many studies have reported strong relationships between mandibular third molar calcification and hand-wrist maturity, but in contrast, Demirjian and Buschang et al. reported a weak relationship between dental maturity and skeletal maturity. A previous research study showed a significantly weak correlation between mandibular third molar and skeletal maturity in females 0.31 and males 0.47 [19], but Ëngstrom and coworkers found a strong correlation between dental maturity and skeletal maturation $(r=0.72)$ [21]. In Thai subjects, mandibular third molar showed the lowest correlation with hand-wrist maturation stage at $r=0.47$ in male subjects, and female subjects $r=0.31$ [24]. In our study, a weak correlation was observed between mandibular third molar and hand-wrist maturation stage, such as in males, it was 0.43 , while in females, it was 0.22 ; however, correlation of mandibular third molar with chronological age was moderate, with females 0.60 and males 0.69 . This result of our study was found to be in accordance with the result of mandibular third molar calcification in the Korean population, having a strong correlation with chronological age [9]. The use of mandibular third molar calcification from other studies or other national standards is certainly not appropriate because it can cause overestimated or underestimated degrees of development [19, $28,29]$. Based on our study, mandibular third molar calcification stage at panoramic radiographs can be used as an adjunctive tool in combination with hand-wrist maturation as a diagnostic tool to estimate the timing of the pubertal growth, especially at prepubertal growth.

\section{CONCLUSION}

The purpose of the study was to determine the sensitivity and specificity of mandibular third molar calcification at chronological age and hand wrist maturation stage to discriminate between female and male at pubertal growth period from 8 years to 17 years. The following conclusions have been obtained.

(1) No significant difference in mandibular third molar calcification stage $\mathrm{B}$ and $\mathrm{C}$ between females and males has been observed, but significant differences were found in mandibular third calcification stage between females and males at stages $\mathrm{A}, \mathrm{D}, \mathrm{E}, \mathrm{F}, \mathrm{G}$ and $\mathrm{H}(\mathrm{P}<0.05)$.

(2) The highest percentage of mandibular third molar crown formation at hand wrist maturation stage in females was at stage D (6.68\%) at SMI-10, and males, it was at stage D $(8.83 \%)$ at stage SMI-4. Root formation in females was at stage $\mathrm{E}(8.24 \%)$ at MP3u, while in males, it was observed at stage F $(4.86 \%)$ at SMI- 10 .

(3) Regarding the sensitivity and specificity of mandibular third molar calcification at hand wrist maturation stage, in females, at S stage, $97 \%$ sensitivity and $100 \%$ specificity were observed, and in males, 94,5\% sensitivity at SMI-2 and $99.99 \%$ specificity have been observed, indicating mandibular third molar calcification to be only useful for diagnosing the prepubertal growth phase.

(4) There was a moderate correlation observed between mandibular third molar stage and chronological age (females 0.60 and males 0.69 ), and low correlation between mandibular third molar and hand-wrist maturation (females 0.22 and males 0.43). This result indicates that mandibular third molar calcification stages might be clinically used as a maturity 
indicator of the pubertal growth period. However, further study is recommended in a larger sample size.

The limitation of our study is that the samples were obtained only from the Deutero-Malay racial group, which is the largest race group in Indonesia, and from the urban city of Bandung that may not represent the socio-economic demographics of the entire population of the Deutero-Malay subjects and other races in Indonesia. Another limitation is that we were unable to control the nutrition, systemic illnesses, sports hobbies or other factors that could affect pubertal growth and development unless based on anamnesis.

\section{ETHICS APPROVAL AND CONSENT TO PARTI- CIPATE}

Ethical approval was given by Health Research Ethical Committee of Faculty of Medicine, Universitas Padjadjaran (Protocol No. 395/UN6.CI.3.2/KEPK/PN/2016).

\section{HUMAN AND ANIMAL RIGHTS}

No animals were used in this research.All human research procedures followed were in accordance with the ethical standards of the committee responsible for human experimentation (institutional and national), and with the Helsinki Declaration of 1975, as revised in 2013.

\section{CONSENT FOR PUBLICATION}

The participants provided written informed consent to be involved in this study.

\section{AVAILABILITY OF DATA AND MATERIALS}

The data sets analyzed during the current study are available from the corresponding author [E.M] upon reasonable request.

\section{FUNDING}

None.

\section{CONFLICT OF INTEREST}

The authors declare no conflict of interest, financial or otherwise.

\section{ACKNOWLEDGEMENTS}

The researchers gratefully acknowledge the Orthodontic Department at Padjadjaran University for research facilities.

\section{REFERENCES}

[1] Hägg U, Matsson L. Dental maturity as an indicator of chronological age: the accuracy and precision of three methods. Eur J Orthod 1985; 7(1): $25-34$

[http://dx.doi.org/10.1093/ejo/7.1.25] [PMID: 3856522]

[2] Mincer HH, Harris EF, Berryman HE. The A.B.F.O. study of third molar development and its use as an estimator of chronological age. $\mathrm{J}$ Forensic Sci 1993; 38(2): 379-90.

[http://dx.doi.org/10.1520/JFS13418J] [PMID: 8454998]

[3] Gunst K, Mesotten K, Carbonez A, Willems G. Third molar root development in relation to chronological age: a large sample sized retrospective study. Forensic Sci Int 2003; 136(1-3): 52-7. [http://dx.doi.org/10.1016/S0379-0738(03)00263-9] [PMID: 12969620]

[4] Ades AG, Joondeph DR, Little RM, Chapko MK. A long-term study of the relationship of third molars to changes in the mandibular dental arch. Am J Orthod Dentofacial Orthop 1990; 97(4): 323-35.

[http://dx.doi.org/10.1016/0889-5406(90)70105-L] [PMID: 2321598]

[5] Almpani K, Kolokitha OE. Role of third molars in orthodontics. World J Clin Cases 2015; 3(2): 132-40.

[http://dx.doi.org/10.12998/wjcc.v3.i2.132] [PMID: 25685759]

[6] Thorson J, Hägg U. The accuracy and precision of the third mandibular molar as an indicator of chronological age. Swed Dent J 1991; 15(1): 15-22.

[PMID: 2035147]

[7] Franklin D, Flavel A, Noble J, Swift L, Karkhanis S. Forensic age estimation in living individuals: methodological consideration in the context of medico-legal practice. Res Rep Forensic Med Sci 2015; 5: 53-66.

[http://dx.doi.org/10.2147/RRFMS.S75140]

[8] Demirjian A, Goldstein H, Tanner JM. A new system of dental age assessment. Hum Biol 1973; 45(2): 211-27.

[PMID: 4714564]

[9] Cho SM, Hwuang CJ. Skeletal maturation evaluation using mandibular third molar development in adolescents. Korean J Orthod 2009; 39(2): $120-9$.

[http://dx.doi.org/10.4041/kjod.2009.39.2.120]

[10] Thevissen PW, Pittayapat P, Fieuws S, Willems G. Estimating age of majority on third molars developmental stages in young adults from Thailand using a modified scoring technique. J Forensic Sci 2009; 54(2): 428-32.

[http://dx.doi.org/10.1111/j.1556-4029.2008.00961.x] [PMID: 19187460]

[11] Arany S, Iino M, Yoshioka N. Radiographic survey of third molar development in relation to chronological age among Japanese juveniles. J Forensic Sci 2004; 49(3): 534-8.

[http://dx.doi.org/10.1520/JFS2003372] [PMID: 15171172]

[12] Bolaños MV, Moussa H, Manrique MC, Bolaños MJ. Radiographic evaluation of third molar development in Spanish children and young people. Forensic Sci Int 2003; 133(3): 212-9.

[http://dx.doi.org/10.1016/S0379-0738(03)00037-9] [PMID: 12787654]

[13] Sisman Y, Uysal T, Yagmur F, Ramoglu SI. Third-molar development in relation to chronologic age in Turkish children and young adults. Angle Orthod 2007; 77(6): 1040-5.

[http://dx.doi.org/10.2319/101906-430.1] [PMID: 18004924]

[14] Deitos AR, Costa C, Michel-Crosato E, Galić I, Cameriere R, Biazevic MG. Age estimation among Brazilians: Younger or older than 18? J Forensic Leg Med 2015; 33: 111-5.

[http://dx.doi.org/10.1016/j.jflm.2015.04.016] [PMID: 26048509]

[15] De Luca S, Aguilar L, Rivera M, et al. Accuracy of cut-off value by measurement of third molar index: Study of a Colombian sample. Forensic Sci Int 2016; 261: 160.e1-5.

[http://dx.doi.org/10.1016/j.forsciint.2016.01.026] [PMID: 26898677]

[16] Cavrić J, Galić I, Vodanović M, et al. Third molar maturity index (I3M) for assessing age of majority in a black African population in Botswana. Int J Legal Med 2016; 130(4): 1109-20.

[http://dx.doi.org/10.1007/s00414-016-1344-1] [PMID: 26972694]

[17] Gulsahi A, De Luca S, Cehreli SB, Tirali RE, Cameriere R. Accuracy of the third molar index for assessing the legal majority of 18 years in Turkish population. Forensic Sci Int 2016; 266: 584.e1-6. [http://dx.doi.org/10.1016/j.forsciint.2016.04.034] [PMID: 27344224]

[18] Fishman S. Maturation stages of the hand and wrist as indicators of the prepubertal growth spurt. Acta Odontol Scand 1987; 38: 187-200.

[19] Demirjian A, Buschang PH, Tanguay R, Patterson DK. Interrelationships among measures of somatic, skeletal, dental, and sexual maturity. Am J Orthod 1985; 88(5): 433-8. [http://dx.doi.org/10.1016/0002-9416(85)90070-3] [PMID: 3864376]

[20] Nolla CM. The development of the permanent teeth. ASDC J Dent Child 1960; 27: 254-63.

[21] Engström C, Engström H, Sagne S. Lower third molar development in relation to skeletal maturity and chronological age. Angle Orthod 1983; 53(2): 97-106. [PMID: 6576657]

[22] Jung YH, Cho BH. Radiographic evaluation of third molar development in 6- to 24-year-olds. Imaging Sci Dent 2014; 44(3): 185-91.

[http://dx.doi.org/10.5624/isd.2014.44.3.185] [PMID: 25279338]

[23] Bassed RB, Briggs C, Drummer OH. Age estimation and the developing third molar tooth: an analysis of an Australian population using computed tomography. J Forensic Sci 2011; 56(5): 1185-91. [http://dx.doi.org/10.1111/j.1556-4029.2011.01769.x] [PMID: 


\section{4]}

[24] Krailassiri S, Anuwongnukroh N, Dechkunakorn S. Relationships between dental calcification stages and skeletal maturity indicators in Thai individuals. Angle Orthod 2002; 72(2): 155-66.

[PMID: 11999939]

[25] Kullman L, Johanson G, Akesson L. Root development of the lower third molar and its relation to chronological age. Swed Dent J 1992; 16(4): 161-7.

[PMID: 1455327]

[26] Lecca-Morales RM, Carruitero MJ, Carruitero MJ. Relationship between dental calcification and skeletal maturation in a Peruvian sample. Dental Press J Orthod 2017; 22(3): 89-96.

[http://dx.doi.org/10.1590/2177-6709.22.3.089-096.oar]
28746492]

27] Perinetti G, Contardo L, Gabrieli P, Baccetti T, Di Lenarda R. Diagnostic performance of dental maturity for identification of skeletal maturation phase. Eur J Orthod 2012; 34(4): 487-92.

[http://dx.doi.org/10.1093/ejo/cjr027] [PMID: 21345927]

[28] Olze A, Bilang D, Schmidt S, Wernecke KD, Geserick G, Schmeling A. Validation of common classification systems for assessing the mineralization of third molars. Int J Legal Med 2005; 119(1): 22-6

[http://dx.doi.org/10.1007/s00414-004-0489-5] [PMID: 15538611]

[29] Mehta N, Patel D, Mehta F, Gupta B, Zaveri G, Shah U. Evaluation of skeletal maturation using mandibular third molar development in Indian adolescents. J Forensic Dent Sci 2016; 8(2): 112 [http://dx.doi.org/10.4103/0975-1475.186372] [PMID: 27555733]

(C) 2021 Mardiati et al.

This is an open access article distributed under the terms of the Creative Commons Attribution 4.0 International Public License (CC-BY 4.0), a copy of which is available at: https://creativecommons.org/licenses/by/4.0/legalcode. This license permits unrestricted use, distribution, and reproduction in any medium, provided the original author and source are credited. 